\title{
Preparedness and Response Strategy: Human Mobility Population Mapping Approach, Health Interoperability, and Informatics to Manage Outbreaks or Pandemics
}

\author{
Abdul Joseph Fofanah ${ }^{1}$, Issa Fofana ${ }^{2}$, Saidu Koroma ${ }^{1}$ \\ ${ }^{1}$ Milton Margai College of Education and Technology now “Milton Margai Technical University”, \\ Department of Mathematics and Computer Science, \\ Goderich Road, Freetown, Sierra Leone \\ abduljoseph.fofanah@gmail.com \\ ${ }^{2}$ School of Technology, Njala University, \\ Department of Physics and Computer Science \\ issa_fofana@hotmail.com
}

DOI: 10.29322/IJSRP.11.10.2021.p11818

http://dx.doi.org/10.29322/IJSRP.11.10.2021.p11818

\begin{abstract}
The emergence of recent outbreaks and the current pandemic have had increasing demands for past and present patient medical information, as preparedness and response strategies, create new data sharing and exchange demands on health information systems (HIS). A review of interoperability technique and human mobility mapping was critically examined and key design requirements during HIS implementations as parameters to improve the current health systems across mobility corridors. This paper also presents a mobility mapping network methodology and to support health authorities for preparedness and response especially areas in the health sectors that require improvement for any infectious diseases and future outbreaks or pandemic transmission. To realize the universal health coverage (UHC), we present some key parameters matrix; level of care, national standards and guidelines, health promotion, health education, safe blood transfusion, mobile clinics and field hospitals, infection control in healthcare settings, and patient safety, and healthcare waste management. The proposed human population mobility mapping (HPMM) methodology is presented with mathematical theories to better understand how human mobility contributes to the spread of infectious diseases within and out of any country's corridor. The aim of the proposed algorithm is to determine the best practices that would be used to address health challenges in the health sectors during or post outbreaks of infectious diseases as a result of human mobility. In the adapted algorithm designed we were able to map out some localities (in) (Sierra Leone and Nepal) using GIS techniques to determine places of high vulnerability. The data was analyzed, and the result obtained shows that the higher the population at a specific locality the greater the chances of contracting the diseases.
\end{abstract}

Index Terms- Preparedness and response, outbreaks, pandemic, electronic health record, information health systems, human population mobility, interoperability

\section{INTRODUCTION}

$\mathrm{T}$ he Coronavirus disease (COVID-19), firstly detected in China in November 2019, has spread throughout the globe to the scale of a pandemic, declared by the World Health Organization (WHO) [1]. Subsequently, the pathogen

This publication is licensed under Creative Commons Attribution CC BY was identified as a novel coronavirus and named severe acute respiratory syndrome coronavirus 2 (SARS-CoV-2) [2]. Following that on January 30, 2020, WHO declared the disease a public health emergency of international concern (PHEIC). The WHO declared that the COVID-19 variant has posed a serious health challenge across nations, and health infrastructure and urged for effective coordination and strategies to enhance preparedness and response to the infection across health domains. The developed nations including the United States of America proclaimed the pandemic a national and international emergency [3]. Apparently, while healthcare systems extend their rapid response and preparedness an increasing clinical demand to avert the rise and incidence of COVID-19 [4, 5].

Fundamentally, the operational management of a pandemic in an outbreak in the era of recent medicine is testing the capabilities of electronic health records (EHR), and essentially important for developing tools that will support standard management of patients-related record systems [6]. Artificial intelligence, machine learning, and deep learning technological tools can effectively enhance institutions during an outbreak or pandemic by expediting the recent widespread distribution of data/information, tracking matrix mechanisms in real-time, creating virtual sites for meeting and daily operations, and possibly most significantly, delivering telemedicine visits for patients [7-10].

During the Ebola outbreaks in West Africa in 2014, the world was brought to attention to the use of the HER as a potential public health tool [11]. The issues of health infrastructure and vulnerability space surrounded by the healthcare sector in relation to human mobility and health risks challenges. However, notwithstanding the recent Ebola epidemic, the infrastructure for outbreak management was not available in many health systems including the US and their HER applications. Consequently, the emergence of the COVID-19 pandemic brought the world on its kneels and possesses the vulnerability capacity of various countries' healthcare infrastructure. Currently, various institutions are working to rapidly develop supportive and consistent informatics infrastructure in order to prepare for managing an exponential increase. Essentially, the review to describe the 
related informatics tools need to effectively manage this novel infection and the variant of the COVID-19 disease is lacking.

Comparatively, and in regard to human mobility matrix, the Ebola disease 2014, severe acute respiratory syndrome (SARS, 2002), Middle East Respiratory Syndrome (MERS, 2012), and currently Coronavirus (COVID-19, 2019) spread throughout various mobility corridors as a result of human and population mobility pattern. Since then, the COVID-19 disease which was detected in Hubei Province, China has spread throughout the world to the extent to be declared as a pandemic by the WHO and as of 16 August 2021, the number of infected cases stands at 207,784,507 including 4,370,424 deaths and 4,462,336,040 vaccines doses have been administered, reported to WHO. Inherently, the spread of viral diseases affirmed that human mobility and inadequate health infrastructure are the major reasons for the high infection rates across many countries.

In 2014, Ebola outbreak in the West Africa region, the International Organization for Migration in collaboration with WHO developed a framework to handle the human mobility matrix for both local and international health regulations (IHR) to mitigate the spread of virus or disease across the mobility corridor. Mobility mapping was developed through an adaption of displacement tracking matrix (DTM) and has been implemented as part of the preparedness and response plan to several outbreaks, specifically the Ebola Virus Disease (EVD), for the Democratic Republic of Congo (2017, 2018-2020), Burundi, South Sudan, and Uganda (2019) as well as the plague outbreak in Madagascar (2018). The main objective of human mobility mapping is to understand the dynamics of human mobility and identify the most vulnerable, priority locations within and outside the border. The synergy of this technique is to enable healthcare sectors, communities, and various actors to limit the spread of infectious diseases and other public health threats, directly affected by human population mobility. In this paper, we present a technique that would handle issues surrounded by healthcare challenges for preparedness and response strategies.

Furthermore, health border and mobility management aims at reducing the spread of communicable diseases through prevention, detection, and response activities along with human mobility corridors and in cross border areas, while enhancing local health systems capacities, intersectoral communication, and partnerships, and international cooperation. The main health framework integrates health and migration management bridging international health security with population-based understating of public health and mobility patterns. Mobility mapping rests on multisectoral health systems strengthening approach aiming to address global health security concerns vis-à-vis the risks of the international spread of infectious diseases and other health threats along the mobility continuum towards ensuring Universal Health Coverage (UHC). A hallmark of human mobility is the integration of mobility pattern data in epidemiological surveillance for meaningful analysis of public health risks and decision-making.

\subsection{Some historical facts about outbreak or pandemics}

One of the deadliest pandemics in history (from 1918-1919) accounted for an estimated death toll ranging from 17 million to 100 million people. The death toll is higher than that of World War 1. About 500 million people about one-third (1/3) of the world's population were infected by the commonly called "Spanish Flu" but did not originate from Spain [12].

During World War 1, Spain was a neutral country with free media that covered the outbreak from the start. Meanwhile, allied countries and the central powers had wartime censors who covered up news of the flu to keep morale high. This is because Spanish news sources were the only ones reporting on the flu, many believed it originated there. "Hypothesis about the source": British troops in France, the major UK troops staging and hospital camp in Etaples in France has been theorized by virologist John Oxford as being the entry of the flu. The historian Alfred W. Crosby stated in 2003 that the flu originated in Kansas, and popular author John M. Barry described a January 1918 outbreak in Haskell Country, Kansas, as the point of origin in his 2004 article [13].

Discovery of the virus: For decades, generations of scientists and public health experts have been trying to discover the virus. In 1951, Swedish microbiologist Johan Hultin obtained lung tissues from bodies buried at a gravesite in a village called Brevig Mission in Alaska. But he failed to retrieve the 1918 virus. In 1997, the molecular pathologist Jeffery Taubenberger at the Armed Forces Institute of Pathology and his group sequenced part of the genome of the 1918 virus. In 1999, Dr. Ann Reid et al at the Armed Forces Institute of Pathology succeeded in sequencing the full-length HA gene sequence of the 1918 virus. In 2005, Taubenberger et al. completed the entire genome sequence of the 1918 virus [14]. The microbiologist Dr. Terrence Tumpey of the Centre for Disease Control (CDC) reconstructed the complete 1918 virus. However, WHO issues best practices for naming new human infectious diseases. "1918 flu pandemic": in 2015 , WHO called scientists, national authorities, and the media to follow best practices in naming new human infectious diseases to minimize unnecessary negative effects on nations, economies, and people. More modern terms for this virus including the 1918 influenza pandemic and the 1918 flu pandemic [15].

\section{HEALTH INFORMATION SYSTEMS}

This section entails the concepts and theories of health systems, interoperability of health systems, designed and overview of interoperability in relation to the 4-Knowings (knowing what, knowing how, knowing which, and knowing who).

\subsection{Health systems}

The World Health Organization (WHO) defines health systems as: "all the organizations, institutions, and resources that are devoted to producing health actions". Subsequently, this includes a range of players engaged in the provisioning, financing, and management of healthcare services, with efforts to influence determinants of health as well as providing direct services, and encompassing all levels: central, regional, district, community, and household or based on country's administrative structural level. In this section of this research paper, six building blocks of the health system framework were identified: leadership, human resources, drugs, and medical supplies, health financing, health information management, and service delivery. The various interconnections and interactions between each of these functions and actions affecting one component can affect the others. These health systems' building blocks are the functions that are required to deliver essential health services. It is expected that health interventions during disaster responses should be designed and implemented in a way that contributes to strengthening health systems. In order to achieve better healthcare services, the following parameters are essential in ensuring the realization of universal health coverage (UHC) objectives: 
Level of care: Provision of health services at the appropriate level of the health system may include household and community, clinic or health post, health centre, and hospital.

National standards and guidelines: To adapt and establish standardized case management protocols for the most common diseases, taking account of national standards and guidelines that are operational in each nation's context

Health promotion: To establish and strengthen a standardized system of triage at all health infrastructure (facilities) to ensure those with emergency signs receive appropriate and immediate treatment.

Health education: To initialize health education and promotion at various levels of the administrative domain including community and health facility levels. The programmability should emphasize the provision of information on the major health problems, health risks, the availability and location of health services and behaviours that protect and promote good health, and address and discourage harmful practices as in the case of the Ebola outbreak in West Africa (2014). Public health messages and materials should be utilized appropriate language and media coverage, being culturally sensitive and easy to understand can mitigate the spread of the diseases at mobility corridors.

Safe Blood Transfusion: Establishment and following safe and rational use of blood supply and blood products. Efforts should be coordinated with the national blood transfusion service (BTS) especially if such a system exists. Good laboratory practice should be established including screening for transfusion transmissible infections, blood grouping, compatibility testing, blood component production, and the storage and transportation of blood products. All these play an important role in ensuring the disease/ communicable disease does not entirely infect other people as a result of human population mobility. Appropriate clinical staff should be trained to ensure the provision of the blood and its effective clinical use.

Mobile clinics and field hospitals: Avoid the establishment of alternative or parallel health services, including mobile clinics and field hospitals. During certain Outbreaks, it is essential to operate mobile clinics in order to meet the needs of isolated or mobile populations who have limited access to healthcare. When existing hospitals are severely damaged or destroyed field hospitals could be the only way to provide healthcare. Essentially, during emergencies (days 3-15) temporary facility surgical and obstetrical can substitute for damaged local hospitals. There is often substantial political pressure from donors and governments to deploy them.

Infection control in healthcare settings and patient safety: Designing and implementing health services in a manner that ensures patients' rights to privacy, confidentiality, and informed consent. During disasters, continuing IPC programs should be enforced at both national and peripheral levels, and at various healthcare facility levels such as defined IPC policies, with qualified and dedicated technical staff (IPC team) to run infection control programs, with defined budget for activities and supplies in response to an emergency.

Healthcare waste: implement appropriate waste management procedures, safety measures, and infection control methods in health facilities. Dispose of dead bodies in a manner that is dignified, culturally appropriate and based on good public health practices. However, during the Ebola outbreak in West Africa (Sierra Leone) unsafe burial practices were adopted by both religious and traditional healers leading to the transmission of the EVD across various mobility corridors in surrounding counties.

\subsection{Interoperability in HIS}

Interoperability in healthcare refers to timely and secure access, integration, and use of electronic health data so that it can be used to optimize health outcomes for individuals and populations. The role of HIS play a significant role in patient care continuity by comparing past medical information and current patient medical record to predict adequate treatment more than ever before [16-18]. The HISs were designed as vertical grain storage with no interoperability obligations [1920]. There are still challenges to protect the capacity to exchange patient information due to challenges posed by multimedia technology [21]. A number of researchers recommend the implementation of HIS that will mitigate from vertical grain storage to horizontally integrated systems to meet the current data sharing information needs [22]. This will facilitate cross-boundary information exchanges and enable researchers to carry out their studies. Nevertheless, the given tradition of designing vertical grain storage systems and the inadequate coordination efforts among HIS initiatives, as limited information is known on how to purposively design for HIS' interoperability [23]. Practically, software engineers rarely depend on interoperability architectures and business model framework to guide both design and development of interoperability between different software [24] without knowing the contextual interoperability challenges they are dealing with and how adequate to resolve them, most of the time interoperability proponents engage in HIS ventures [25]. Subsequently, this has resulted in various failed HIS interoperability ventures as denoted by Benson T. and Grieve G. [26].

On the other hand, when design objectives are not matched to reality objectives, there are greater chances of HIS implementation when contends in the design-reality gap model [27]. Again, whenever the interoperability principle is not matched to the context of integration or missing the chances of system implementation failure is high [28]. Some authors argue for a thorough analysis of the context of integration in order to get a clear prescription of interoperability design prerequisites that are inherent to all participating entities into a set of system design requirements [29]. From a software engineering perspective to derive well-defined system design requirements and the following argument was presented:

- For goal-driven requirement, elicitation processes are necessary and collaborative view that encapsulates contextual factors and best practices

- To stir-up interoperability inclusiveness onto future HIS implementation schedules, the goal-driven technique is adequate. Notwithstanding, the elicitation scheme is not just a collection of design requirements but a process that entails discovery, emergence, and new development. In order to foster collaborative requirement elicitation approaches from the domain of organization research that can foster highly recommended communicative methods and elicitation approaches [30].

\subsection{Designing for interoperability}

Interoperability capabilities can inherently be designed into systems that can be fitted into systems whenever the needs arise [31]. However, HIS projects are centred on designing and developing interoperability capabilities between systems that are really in practice, since interoperability is usually not a design prerequisite [32]. Additionally, related literature mainly focuses on HIS implementations and adoption with a limited 
focusing on HIS interoperability interventions [33-34]. Interoperability is a capability that is required to inherently develop and be designed with systems. West C. [35] further showed that good designed and solutions do not just emerge they must and should be purposively designed and thus reflect the purposely to design HIS interoperability capabilities. The preposition of inherently designing interoperability between systems was put forward by several authors [36-39]. Interoperability capabilities must be designed to enhance and facilitate semantic interoperability between the systems. Thus, semantic interoperability will require the same interpretation and meaning of the shared information heterogeneity [40].

The healthcare information and management systems society (HIMSS), defined interoperability as "the ability of health information systems to work together within and across organizational boundaries in order to advance the health status of, and the effective delivery of healthcare for individuals and communities" [41]. However, there are prerequisites for health information systems to possess the ability to work together across organizational boundaries. For instance, according to ISO (2004) standard [42], all systems proposed to collaborate by substituting information must do so according to a specified technique. This ISO standard points to an important consideration of specifying and designing a technique of information exchange between systems to be involved in any information exchanges. Consequently, for any information interchange between systems, a communication channel known as an interoperability principle must be presented [43]. Kobusinge G. [44] presented three main interoperability principles: unification, intersection, and inter-linking. Using unification, a 'one common system' principle is applied, intersection principle a common shared information space for all participating systems is designed. Interlinking systems are designed to swap messages between participating systems. Ultimately the participating systems can be independent but be able to share and swap the needed information through platform-independent technologies. Through 'design attitude', interoperability onto HIS implementation agendas can be productive and might surface new possibilities for forecasting HIS interventions.

In Kobusinge G. [44] inspired by Landgren [45] they put forward the design implications for emergency information systems as 'Knowing Where' and 'Knowing What' after applying a sense-making perspective. Kobusinge presented four categories of knowing who, knowing what, knowing who, and knowing which as described:

Knowing Who: To identify and setup skilled steering and implementation teams. Protect upper management involvement Ing and funding.

Knowing What: To identify recent interoperability (data/information sharing) challenges. Design for interoperability can be purposively deduced. Understanding the recent gaps in the context of integration that might affect or promote interoperability.

Knowing How: Evaluate the context of integration and analyse alternative interoperability standards to pursue. Plan for semantic interoperability such as terminology and messaging standards or other sharing strategies like APIs. Involvement of stakeholders, change management, communication plans, and the whole project.

Knowing Which: To focus on informatics such as vital minimum data requirements, standard patient records to be shared (attribute, or optional information). Following legal and policy procedures and outcomes agreed upon for help or to guide future improvements. Identifying outcomes and proposed ideas of interoperability design prerequisites that can guide future HIS interoperability implementations and implication of the analytical strength of the sense-making framework in evaluating design requirement systems design and implementation (see Fig.)

\section{RESEARCH METHODOLOGY}

National context and consultations: To enable the implementation of human mobility mapping across mobility corridors, some preliminary activities need to be conducted. The methodology to track people's mobility and mapping could be presented to stakeholders at the national and local levels. Stakeholders such as Ministry of Health (IHR focal Point, Disease Prevention and Control), Office of National Security, and United States Centers for Disease Control and Prevention (CDC), World Health Organization (WHO), eHealth, DFID, Surveillance Implementation partners, technical institutions with healthcare capacity, and cross border surveillance technical working group in order to consolidate and handle health systems challenges across mobility corridors. Furthermore, several would need a high level of consultations with the IHR focal point to discuss the issues around population mobility and public risks and to identify the national level officers to participate in the development of the framework and implementation. Health and non-health officers are required to be identified by the directorates and various health policymakers including the CDC and IPC unit.

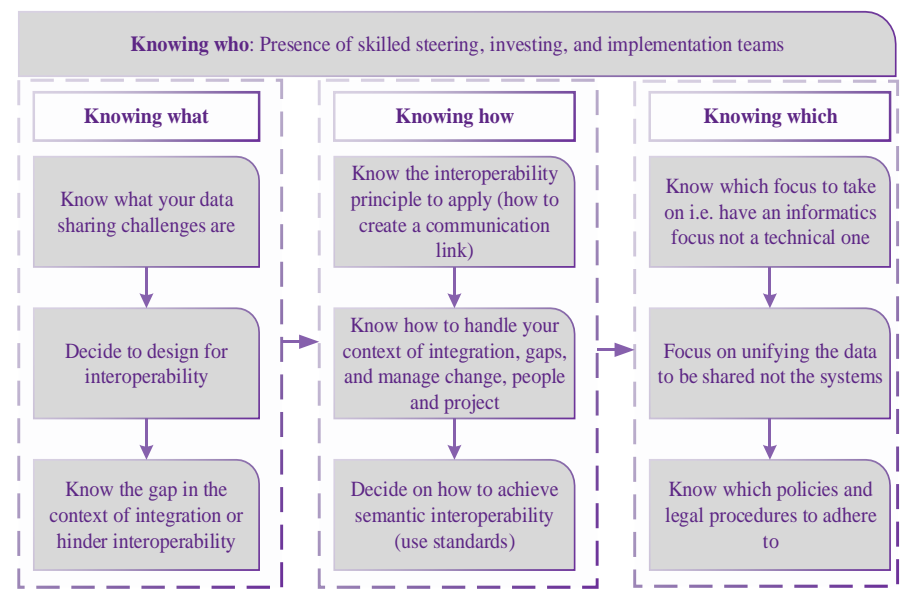

Figure 1: Set of interoperability design prerequisites using the 4Knowing parameters

Required Training: Some training days are required to be conducted to introduce the human mobility mapping and public health risk methodology. The participants should be included at various key stakeholders in the healthcare domain and border officers who understand the context of human mobility across various congregational gatherings within and across the border areas. During the training, participants could be taken through the 3 phases of data collection for the mobility mapping methodology: participatory mapping to identify priority areas/locations, field observation to assess the vulnerabilities and health system capacities, and quantitative data collection through flow monitoring points (FMP). These phases of the method are presented in Figure 2. and explained in detail.

\section{Phase I: Participatory Mobility Mapping}

Here, cross-border communities should be engaged through their leaders or traditional leaders to identify the most 
appropriates key informant groups who can provide the most accurate needed information regarding population mobility patterns in their communities. All the possible key informant groups should be listed and ranked to select of first important people based on the knowledgeability of those areas (5 key persons or groups) who could provide the most appropriate information (could be the best source of in-depth information). Interviews should be conducted usually moderated by a facilitator and assisted by some notetakers and a GIS expert or mapper who understand routes across those areas. These key informant groups are exposed to the map (selected areas under the surveillance of population mobility), receive an orientation of the map. The facilitator then guides the key informants systematically to identify and rank the priority locations (mostly, 5 locations) based on the volume of the population passing or using these sites, designing vulnerability spaces on the map.

Data (from the map and the note-taker guides) is edited and entered in tool/software that generates the priorities areas taking into consideration a weighting system build on the information gathered from different sources and attribute to each assuming vulnerabilities factors that can increase the health risk in the area. Such vulnerability factors may include: the number of the population crossing a specific point of entry (POE) or landing in the Wharf. Data could be compiled with existing information on mobility (maps, georeferenced data) and analyzed to generate the priority locations with the various sites of vulnerability therein (see Figure 3). Priority locations/ sites of vulnerability include points along the mobility continuum where the risk of pathogen transmission and spread of disease/health threats is heightened as a direct result of human mobility.

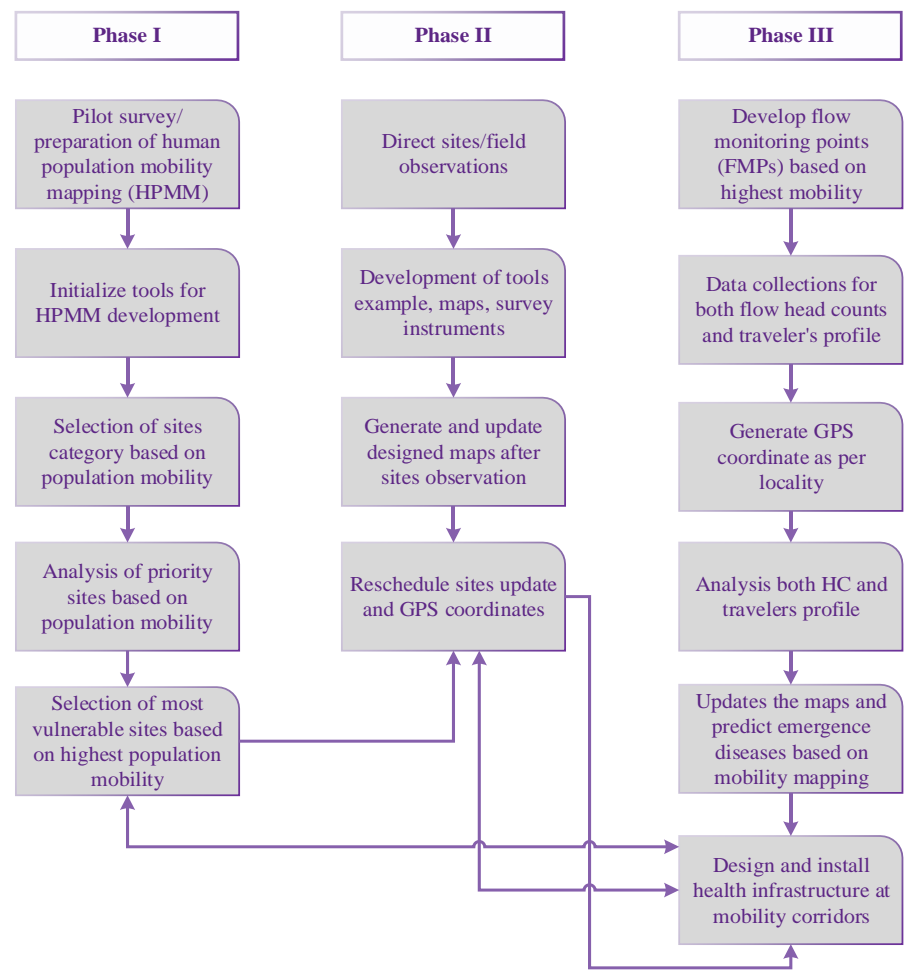

Figure 2: The three phases of the human population mobility mapping methodology

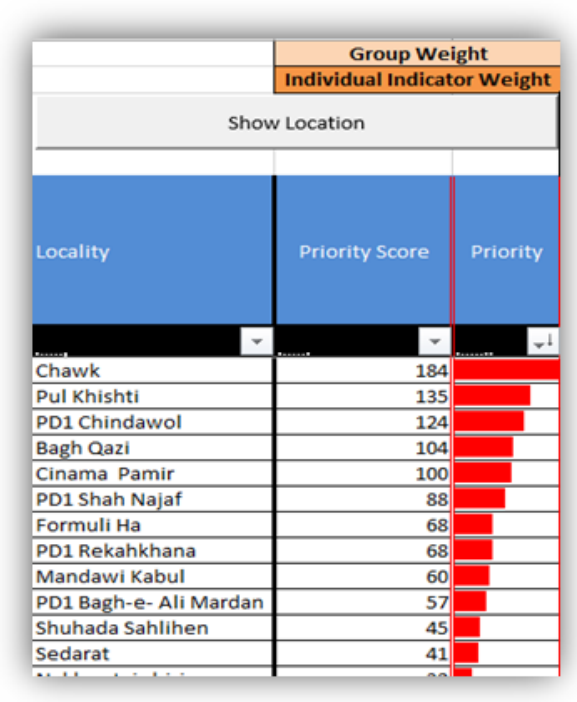

Figure 3: Vulnerability capacity showing the most vulnerable sites and site's location generated by the matrix analysis

\section{Phase II: Field Observation}

Field observation data is intended to provide a deeper and richer understanding of the priority locations and vulnerability sites therein (identified during participatory mapping). It is an opportunity to assess the vulnerability and the capacity of the sites in reducing the spread of infectious disease through prevention, detection, and response mechanisms in place.

During this phase, field teams move to the location /site (with the authorization of the Paramount Chief and the District Medical Officer) and observe, ask questions, take photos (if authorized). A checklist that assesses vulnerability or capacities (including preparedness, health system capacities) is administered. A checklist has to adapt to assess different vulnerabilities/ capacities in the vulnerable sites. Spaces of vulnerability include Markets, Health facilities, Border crossing points, Traditional healer areas, places of worship, places of entertainment, landing sites/wharves, Bus or car stations, Schools, main roads, junctions, and bridges. This data is entered directly on the Kobo collected systems software on tablets and thereafter cleaned are uploaded to the main server in Freetown. Data, therefore, download for analysis purposes using Excel.

\section{Phase III: Quantitative Data Collection}

Quantitative data collection follows a sampling methodology defined by clear presence of mobility flows and number of flows. The field data to be collected would basically be an estimate from 'Key Informants' and would be later used to cross check and confirm or update the population mobility flow against the change. Data on the demographic and socioeconomic profiles of travelers, trave intentions, health screening information (temperature, etc.) during an outbreak. Mobility patterns and the vulnerability factors are analyzed in the context of the public health event/risk to guide resource allocations and response needs. The algorithm for the population mobility mapping framework is represented by Figure 3.

Objectives: The main aim of this paper is to present a thematic and better technique to respond to public health threats which has direct connection to human population mobility. This would enable governments across various sectors to prepare their health infrastructure and subsequently handle any emerging outbreaks or pandemic. In carrying such research 
work the following are key objectives that will enable people to break down the transmission rate of any viral diseases.

- Identify traveler's profiles and mobility patterns have health related impacts both within and or outside the human mobility localities

- Identify most vulnerable places where people or mobile population gathered an interact other or with local communities, which are at risk of both contracting and spreading infectious diseases and other public health threats.

- Identify priority sites or localities with limited capacity to prepare and respond to public health emergency of both local and international concerns.

- Identify priority public health actions and resources allocations, in order to develop action plans aimed at strengthening public health emergency, preparedness, and response strategies ad across various countries border areas and places of high human mobility.

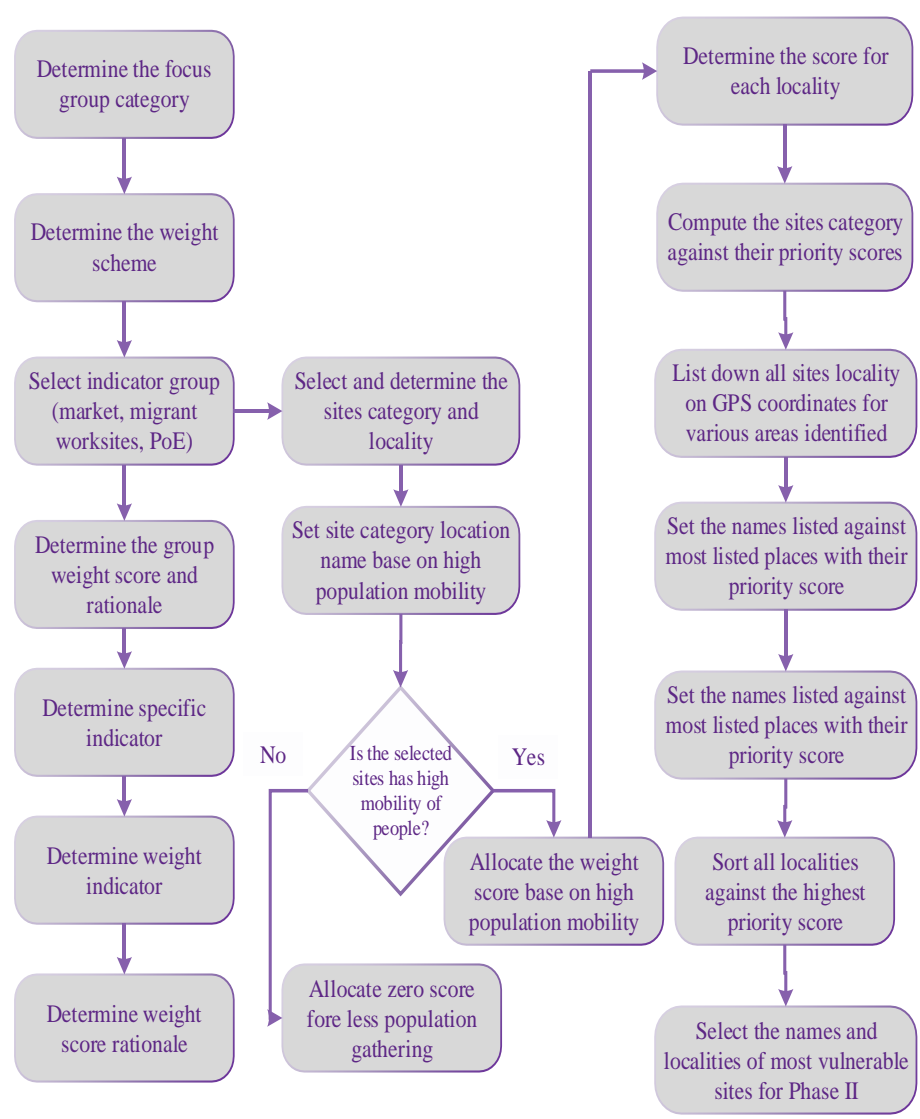

Figure 3: HPMM proposed algorithm and methodology

\section{MATHEMATICAL MODEL OF HPMM METHODOLOGY}

\subsection{Estimating fluxes dynamic of mobility}

The mobility of both influxes and outfluxes of people between pairs of localities at various areas identify $L(i, j, t)$ can be used to estimate the population mobility networks with given mobility events $M_{E 1}-M_{E n}$. The incremental number of individuals, $N(z, t)$, in each mobility gathering area $z\left(M A_{1}-M A_{n}\right)$ during each time period $t$ can be estimated: $N(z, t)=\sum_{t}^{t} G_{t} \Delta N(z, t)$, where the change in the number of individuals $\Delta N(z, t)$ corresponds to the sum of the influxes minus the sum of outfluxes, $G_{t}$ the given time period and thus given by the function:
$\Delta N(z, t)=\sum_{i \neq z}^{n} L(i, z, t)-\sum_{j \neq z}^{n} L(z, j, t)$

In this approximation, the sum of the influxes $\sum_{i \neq z}^{n} L(i, z, t)$ and the sum of the outfluxes $\sum_{j \neq z}^{n} L(i, z, t)$ denote the number of individual arriving at locality $z$ and the number of individuals leaving locality $z$ during a time $t$, respectively, where $n$ is the total number of mobility connections and $t$ begins at specific time of the day and end at midnight everyday (starting or opening to end or closing of the locality). The incremental number of individuals $N(z, t)$ could be set to zero for each locality from a specified time period.

During weekdays and weekends, the average incremental number of individuals each time period $t_{p}$, represented as $\left\langle N\left(z, t_{p}\right)\right\rangle$, could be measured separately because of their different and inherently consistent mobility pattern. The difference between $N$ and average $\langle N\rangle$ is the excess number of individuals:

$N_{E x}(z, t)=N(z, t)-\left\langle N\left(z, t_{p}\right)\right\rangle$

For a locality during a time period, we can scale a factor $R(z)$ to develop an approximation of human population mobility $\operatorname{Pop}(z, t)=N_{E x}(z, t) * R(z)$ related for contributions to $N_{E x}(z, t)$ by automobile users, motorbikes, and bus passengers. The factor $\mathrm{R}(\mathrm{z})$ for a locality is defined by the equation [2]

$R(z)=R_{\text {car }}(z) \times \frac{V_{\text {bus }}(z)+V_{\text {bike }}(z)+V_{\text {taxi }}(z)}{V_{\text {bike }}(z)+V_{\text {taxi }}(z)}$

Where the parameters $V_{\text {bus }}(z), V_{\text {bike }}(z)$, and $V_{\text {taxi }}(z)$ are the estimated daily average trip volumes of bus passengers, motorbikes, and taxi passenger for each locality $z$, respectively. If we assume that certain groups of travelers gathering for a special event, for uncoordinated event are not likely to use the same official routes or to stay within residents, migrant worksites, business areas where entry permission is required. Therefore, a worst-case scenario assumption is that the high population mobility will reside in the public space of a locality where high mobility gathering of people takes place. Hence, we defined high population mobility density $\rho$ and is approximated as:

$\rho(z, t)=\frac{\operatorname{Pop}(z, t)}{A_{c}(z)}$

Where $\operatorname{Pop}(z, t)$ is the large population mobility gathering, $A_{c}(z)$ is the accessible public area within the locality where the high gathering of people event to take place.

\subsection{Generating irregular mobility connections}

In order to determine mobility flux patterns (influx and outflux) related to high mobility gatherings and at mobility corridors, we develop the concepts of irregular mobility connections. In an irregular mobility connection, a directed link from locality or traffic locality $i$ to locality or traffic locality $j$ is generated if the abonormality measure $\delta(i, j, t)$ of the mobility flux $L(i, j, t)$ exceed a threshold $\delta_{\text {threshold }}$.

$\delta(i, j, t)=\frac{L(i, j, t)-\left\langle L\left(i, j, t_{p}\right)\right\rangle}{\sigma\left(L\left(i, j, t_{p}\right)\right.}>\delta_{\text {threshold }}$

Where $L\left(i, j, t_{p}\right)$ and $\sigma\left(L\left(i, j, t_{p}\right)\right)$ are the mean and standard deviation of mobility flux $L(i, j, t)$ in time period $t_{p}$ is the weekday or weekend time of day to which the specific time period $t$ belongs.

To determine the threshold $\delta_{\text {threshold }}$ in equation [5], we need to understand the similarity between two probability distributions, which is usually used and put forward by JensenShannon divergence, and we then developed to determine the 
threshold. The $\delta_{\text {threshold }}$ for discriminating irregular mobility fluxes and regular mobility fluxes. However, the JensenShannon $I S D(P \| Q)$ is based on Kullback-Leibler (KL) divergence (Lin, 1991), and is fined by the equation [6].

$I S D(P \| Q)=\frac{1}{2} D_{K L}(P \| M)+\frac{1}{2} D_{K L}(Q \| M), M=\frac{1}{2}(P+Q)$

Where the KL is the divergence and is given by:

$D_{K L}(P \| M)=\sum_{x} \frac{P(x) \log P(x)}{M(x)}$

And is a measure of the non-symmetric difference between two probability distributions $P(x)$ is the probability that the normalize mobility flux:

$$
L_{n}(i, j, t)=\frac{L(i, j, t)}{\sum_{i} \sum_{j} L(i, j, t)}
$$

The mobility flux function (equation [8]) is a link in an irregular connection during a high mobility gathering of people event is equal to $x$, whereas $Q(x)$ is the probability that $L_{n}$ of a network in an irregular mobility interlink during the same period of regular day is equal to $x$. From equation [8], $\sum_{i} \sum_{j} L(i, j, t)$ denotes the total of mobility fluxes between each pair of localities $i, j$ in an irregular mobility network.

\subsection{Theoretical model approaches}

During and within irregular mobility connection interlinks, high mobility gathering in-degree $M_{i n}$ emerges in the population gathering process and hence enable stakeholders, scientists, and authorities in health systems to provide an effective and efficient way to identify places of high vulnerability as a result of human mobility across many pathways. To derive the mathematical function, we set the total number of trips to $T_{\text {trip }}=n^{2}$. The in-degree of the mobility locality, uniformly distributed attraction strength $P(\eta)$ and production strength $P(\psi)$ are used:

$\forall \eta(i)=\frac{1}{n}, \forall \psi(i)=\frac{1}{n}$

From equation [9], the attraction strength and the production strength of each locality $i$ are both equal to $1 / n$. Assigning the $T_{\text {trip }}$ is a typical Bernoulli trial, the mobility flux $L(i, j)$ between a pair of localities $i$ and $j$ follows a Binomial distribution put forward by Ross, 2014.

$L(i, j) \sim B\left(n^{2}, \frac{1}{n^{2}}\right)$

Therefore, the mean and standard deviation of $L(i, j)$ are obtained (Ross, 2014)

$$
\begin{aligned}
& \langle L(i, j)\rangle=n^{2} \times \frac{1}{n^{2}}=1 \\
& \sigma(L(i, j))=\sqrt{n^{2} \times \frac{1}{n^{2}} \times\left(1-\frac{1}{n^{2}}\right)}
\end{aligned}
$$

However, we assume that population mobility gathering event occurs at a locality $z$ in one day of the $D$ observations days. The attraction strength of gathering stage rather that population or gathering dispersion stage the production strength of locality $z$ is set to $R_{\psi}=1$. The probability that a trip is assigned from a locality $i$ to the population mobility locality $z$ is represented by:

$P_{m}=\psi(i)+\eta(z)=\frac{1}{n} \times \frac{R_{\eta}}{n}=\frac{R_{\eta}}{n^{2}}$, s.t.,$R_{\eta} \ll n$

The mobility flux $L(i, z)$ from a locality $i$ to population mobility locality $z$ also follows a Binomial distribution.

$$
\begin{aligned}
& \grave{L}(i, z) \sim B\left(n^{2}-\frac{R_{\eta}}{n^{2}}\right) \\
& \langle\grave{L}(i, z)\rangle=n^{2} \times \frac{R_{\eta}}{n^{2}}=R_{\eta}
\end{aligned}
$$

A link is generated in an irregular mobility connection when

$$
\delta(i, z)=\frac{\grave{L}(i, z)-\langle\underline{L}(\mathrm{l}, z)\rangle^{D}}{\sigma(L(i, z))^{D}}>\delta_{\text {threshold }}=3
$$

Where $\langle L(i, z)\rangle^{D}$ and $\sigma(L(i, z))^{D}$ are the mean and standard deviation of mobility flux from a locality $i$ to the population mobility locality $z$ during the $D$ observation days. The probability that mobility flux $\hat{L}(i, z)$ through generating a network in the irregular mobility connections can be computed as:

$$
P(\grave{L}(i, z))>L_{\text {threshold }}
$$

Where $L_{\text {threshold }}$ is the mobility threshold and equal to the function:

$L_{\text {threshold }}=\left\langle\langle L(i, z)\rangle^{D}\right\rangle+\delta_{\text {threshold }} \times \sigma(L(i, z))^{D}$

Under the condition that population mobility gathering event rarely occur, we can estimate $\langle L(i, z)\rangle^{D}$ and $\sigma(L(i, z))^{D}$ :

$\langle L(i, z)\rangle^{D} \approx\langle L(i, z)\rangle=1, \sigma(L(i, z))^{D} \approx \sigma(L(i, z)) \approx$

1 , and $L_{\text {threshold }} \approx 4$

To estimate the probability density function (PDF) of the mobility matrix flux $\hat{L}(i, z)$ by a normal distribution with better features than Binomial distribution we obtained:

$P D F\left(\mu=R_{\eta}\right)=\frac{1}{\sqrt{2 \pi R_{\eta}}} e^{-\frac{\left(x-R_{n}\right)^{2}}{2 R_{\eta}}}$

By utilizing the estimated Normal distribution of $\grave{L}(i, z)$, the normalize in-degree $K\left(R_{n}\right)=\frac{M_{i n}}{n}$ of the population mobility locality $z$ is obtained as:

$K\left(R_{\eta}\right)=1-\operatorname{CDF}\left[4 ; \mu=R_{\eta}, \sigma^{2}=R_{\eta}\right]$

$\approx 1-\frac{1}{2}\left[1+\operatorname{erf}\left(\frac{4-R_{\eta}}{\sqrt{2 R_{\eta}}}\right)\right]$

Where $C D F$ is the cumulative density function, and the error function is $\operatorname{erf}(x)=\frac{2}{\sqrt{\pi}} \int_{0}^{x} e^{-w^{2}} d w$. The normalized in-degree $K\left(R_{\eta}\right)$ is computed using original Binomial distribution of $\grave{L}(i, z)$ for the difference.

Another irregular in-degree $K_{\text {in }}$ precedes the maximum population mobility density within a specified period (in hours), providing an effective way to draw stakeholders or authorities attention for large population gathering events at the early stage in order to strategies mechanism that will mitigate public health risks. The dynamics of normalized in-degree $K(t)$ is assumed to follow each of the three mathematical functions in equations [22], [23], and [24], respectively.

$$
\text { Triangular: } K(t)=\left\{\begin{array}{c}
\frac{2 t}{\pi} K_{\max }, 0<t \leq \frac{\lambda}{2} \\
\frac{2(\lambda-t)}{\lambda} K_{\max }, \frac{\lambda}{2}<t \leq \lambda . \\
0, \text { other }
\end{array}\right.
$$

Quadratic: $K(t)=-4 \frac{K_{\max }}{\lambda^{2}} t^{2}+4\left(\frac{K_{\max }}{\lambda} t\right), t \in[0, \lambda]$

Gaussian: $K(t)=K_{\max } e^{-\left(\frac{t-\frac{\lambda}{2}}{\frac{\lambda}{4}}\right)^{2}}, t \in[0, \lambda]$

The empirical results are obtained from the three mathematical functions (equations [22-24]). The three mathematical functions have similar time varying patterns with the three equations, $t$ represents a time period in the population mobility 
gathering stage during which population gathering density $\rho$ increases from 0 to its maximum value $\rho_{\max }$ The specified time period during $\rho=\rho_{\max }$ is represented as $t\left(\rho_{\max }\right)$ and time period during $\rho=0$ and is represented as $t\left(\rho_{0}\right)$. The period of the population gathering stage is $\lambda=t\left(\rho_{\max }\right)-t\left(\rho_{0}\right)$.

The time when the population mobility gathering event is identified is solved by the equation $K(t)=K_{m}$ where $K_{m}$ is the threshold normalized in-degree. The population mobility gathering alert the time $t\left(K_{m}\right)$ is calculated for $(K D)$ following triangular function, quadratic function, and Gaussian function respectively.

Triangular: $t\left(K_{m}\right)=\frac{\lambda}{2} \frac{K_{m}}{K_{\max }} \leq \frac{\lambda}{2}, K_{m} \in\left[0, K_{\max }\right]$ is a challenge (vulnerability) including informal crossing points which most travelers utilize when there are restrictions imposed across mobility corridors.

In some countries especially developing countries where health infrastructure faces enormous challenges, people at remote areas cannot access the health centres easily due to inaccessibility of roads and the distance between their locations the health centres. Consequently, people depend on some of the traditional healers to address their health issues. However, due to the poor or inadequate practices of these traditional healers can contribute to the spread of infectious diseases for instance Ebola outbreak in West Africa. The traditional healers in some countries are integral to most of health systems and its neigbhour borders (see Map 4 and 5).

Quadratic: $t\left(K_{m}\right)=\frac{\lambda}{2}\left(1-\frac{\sqrt{K_{\max }\left(K_{\max }-K_{m}\right)}}{\sqrt{K_{\text {max }}^{2}}}\right) \leq \frac{\lambda}{2}, K_{m} \epsilon[0$, Gaussian: $t\left(K_{m}\right)=\frac{\lambda}{2}-\frac{\lambda}{4} \sqrt{\log \frac{K_{\max }}{K_{m}}} \leq \frac{\lambda}{2}, K_{m} \epsilon\left[\frac{K_{\max }}{e^{4}}, K_{m}\right]$

We used the empirical $K_{\max }$ and $K_{m}$ values to determine the population mobility gathering events to approximate the range of $t\left(K_{m}\right)$. These three mathematical functions can be utilized to determine the dispersion (mobility flow networks) of data/information in relation to human mobility withing specific key areas for large gathering of people.

\section{DISCUSSIONS AND RESULTS OF HPMM}

In this section, we present a database scheme for the analysis of the proposed HPMM methodology and mobility networks. The analysis is presented in two main folds: firstly, the maps showing the various localities that were mapped in both Nepal and Sierra Leone indicating their mobility pattern matrix, and secondly, some prototype for some of the key indicators that may contribute to the spread of infectious diseases as a result of human mobility we referred to as vulnerability. However, the analysis did not encapsulate all the parameters that contribute to human mobility and the transmission of infectious diseases.

\subsection{Human population mobility mapping prototype}

The human population mobility mapping prototype (HPMMP) indicates some of the major contributors to the spread of infectious diseases in connection to human mobility within and or out of the country's corridors (borders) at both national and international borders of the mobility consortium.

In order to understand the mobility pattern matrix, we conducted a study in Nepal (Mechinagar municipality). The main idea of the research is to understand the movement across some specific areas so that health authorities would be able to map out strategies across various health infrastructures to address health challenges in relation to human mobility patterns. The study encapsulates health centres, traditional healers, schools and colleges, transport stations, points of entry, and so on (see Map 1). Furthermore, we analyze the movement of people, hotspot areas, and route accessibility at some of the border municipalities in Nepal (Sidhartnagar and Mechinagar) and some of the chiefdoms (Gbinle Dixing and Bramaia). This will provide a clear road map in addressing future outbreaks and infectious diseases as a result of human mobility (see Map 2). In Map 3, various sites or localities were identified with GPS coordinates analysis which helps us to know areas of hotspots and places where health infrastructure

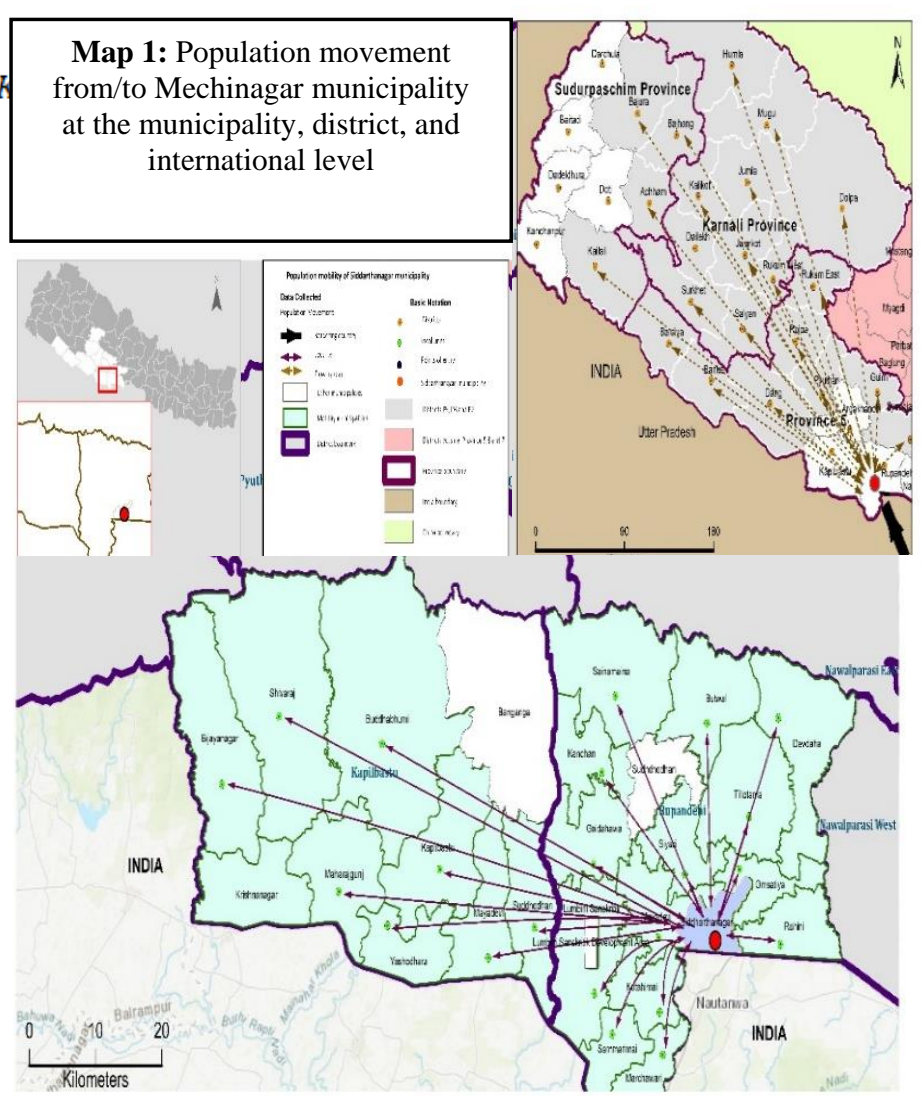




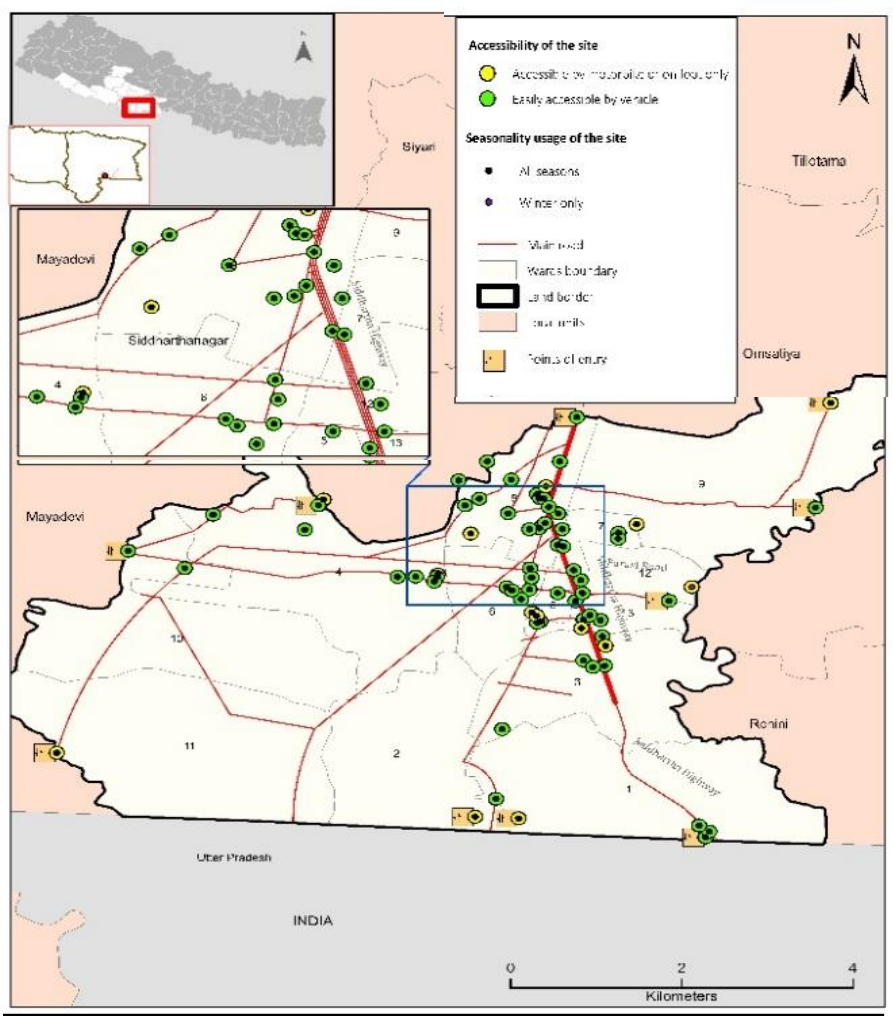

Map 2: Hotspot of human mobility gathering and places of vulnerability between Nepal and India

\subsection{Some key indicators/parameters of HPMM analysis}

Figure 4.1, the top of the bar (right side) shows the main purposes patients visit the health centres and the main purposes of visitors coming from India (left). The analysis shows that diarrhea and typhoid (23.5\% and $17.6 \%$, respectively) are the major factors for people to seek healthcare. On the other hand, people coming from India mostly visit the health centres in Mechinagar municipality to treat and visit patients, with a percentage distribution of 55.6 and 38.9, respectively. This means that people from India who go to the assessed health centres are medical practitioners whose primary objective is to treat or support the health service delivery in Nepal. During a pandemic or an outbreak, there are always concerns on how people should respond to emergency cases of affected people. The study revealed that malaria, dengue, typhoid, and COVID19 are the major diseases affecting people in Mechinagar Municipality, with a percentage distribution of 19.2, 17.3, 15.4, and 13.5, respectively. Therefore, typhoid, malaria, and dengue are the most prevalent diseases prior to and during the pandemic, as of October 2020 (see Figure 4.1 bottom).

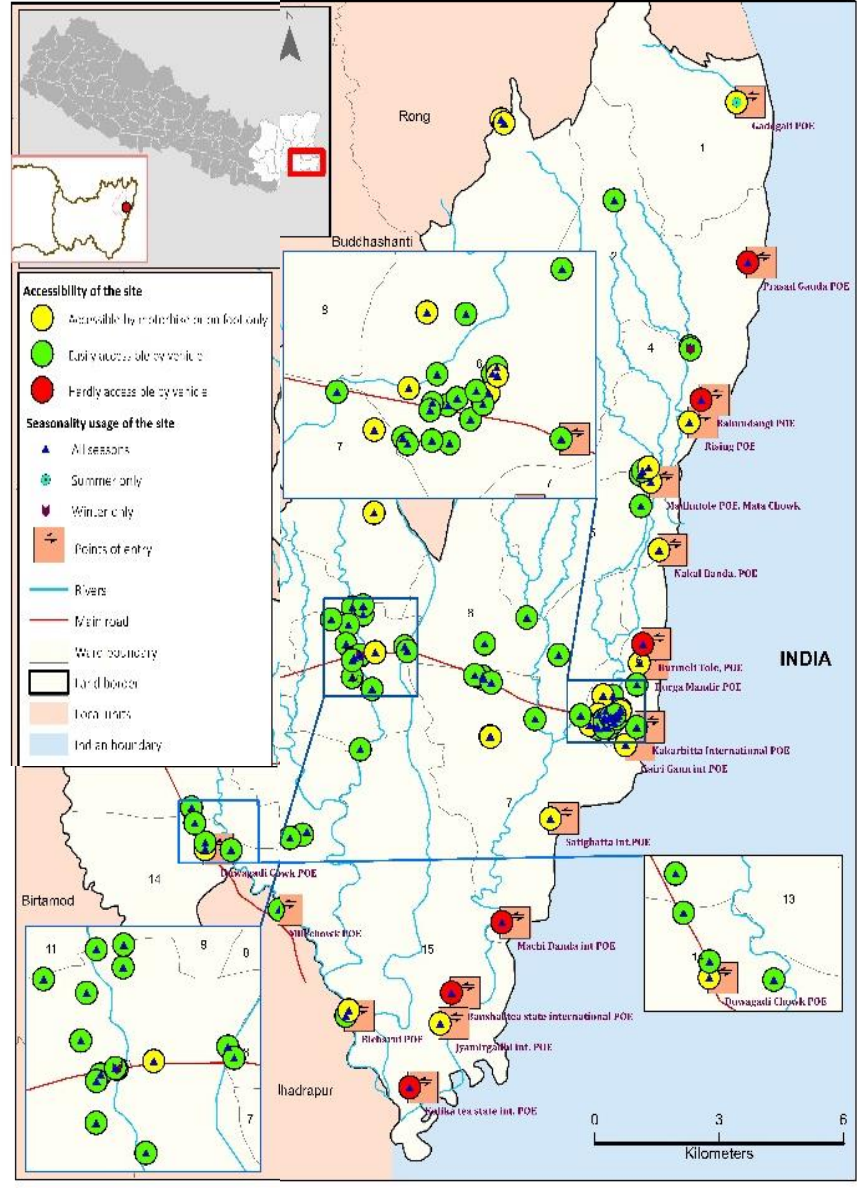

Map 3: Accessibility and seasonality usage of the identified vulnerable sites in Mechinagar (Nepal) Nepal and India

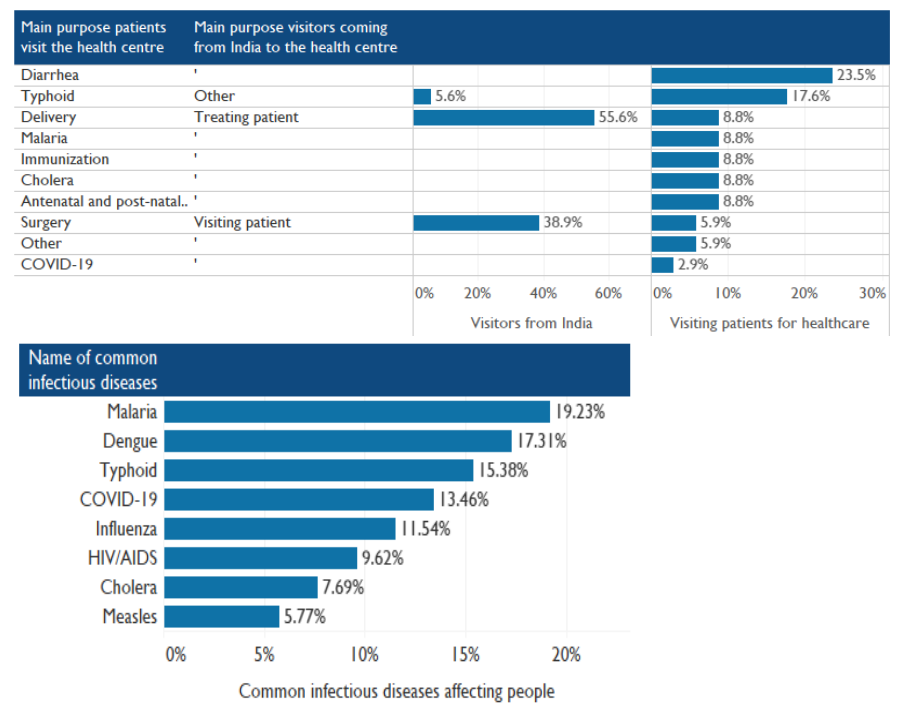




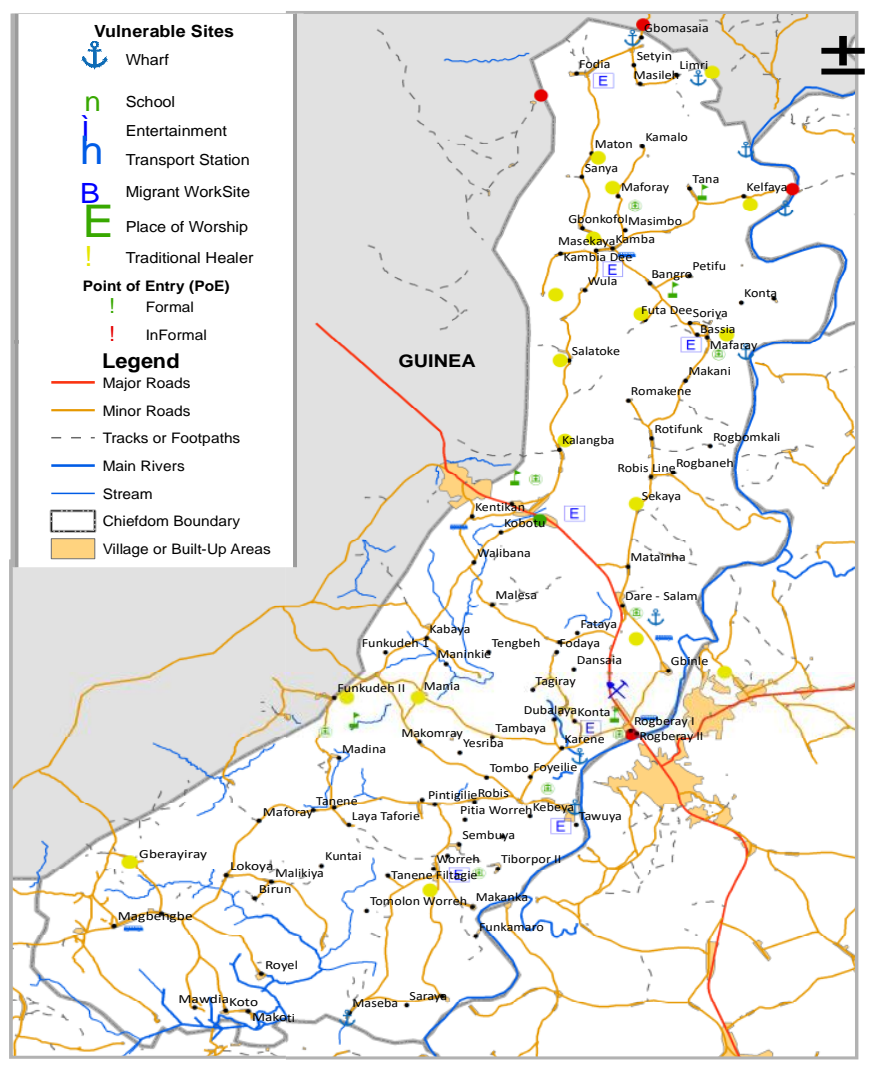

Map 4: Map of Gbinel-Dixing Chiefdom in Sierra Leone showing most vulnerable sites of traditional healers Nepal and India

Figure 4.1: The main purpose patients visit the health centres and visitors coming from India to Nepal health centre (top) and common infectious diseases within Mechinagar locality in Nepal (bottom)

According to the analysis, headache, mental illness, and fever (16.1\% and $12.5 \%$ each, respectively) are the most common diseases treated by traditional healers (see Fig. 2.6 top). These are followed by yellow fever $(10.7 \%)$, STI and other related diseases ( $8.9 \%$ each), abdominal pain $(7.1 \%)$, skin diseases, lower abdominal pain, fracture, diarrhea (5.4\% each), and measles $(1.8 \%)$. The types of practices performed by the traditional healers, which account for the main reasons of patients' visits, in order of importance, include disease cure $(30.3 \%)$, bone setting, mental illness, and other related diseases (15.2\% each), protection (12.1\%), divination (9.1\%), and love password (Mohani) $(3.0 \%)$.

The major reasons for people's movement across the BCPs/POEs and other sites with high mobility were also explored and identified as follows; trade/market/commerce, employment, industry/mining/plantation/timber, transportation, and visit of relatives and/or friends account for the highest, with a percentage distribution of 20.4, 19.4, 13.3 each, and 12.2, respectively, similar to the findings obtained in other municipalities, except for employment, visit of relatives or friends, and industrial activities. This show that the main reasons migrant travel across the POEs and other sites are for economic activities, employment, and industrial activities, such as mining, plantation, or timer logging (see Figure 4.2).
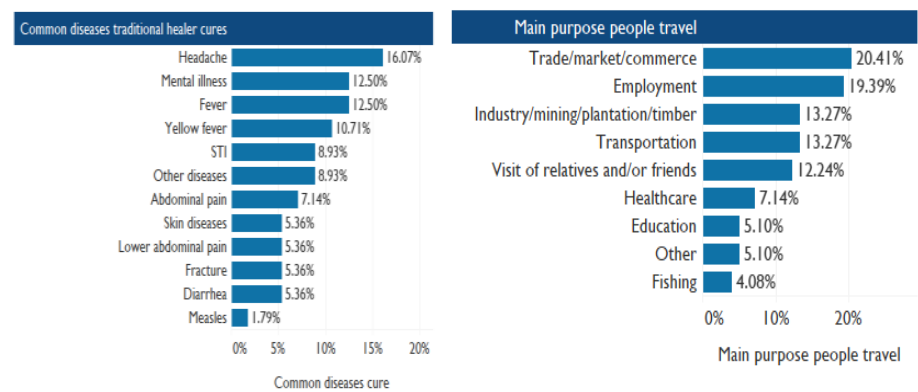

Figure 4.2: Common diseases the traditional healer cures (left) and the main purpose people travel across mobility corridors (right)

Figure 4.3 shows the places from which people seek alternative healthcare when they fall ill. Most people seek help from clinics or hospitals, home treatment, traditional healers, and pharmacy, in order of importance, with a percentage distribution of $61.0,19.5$, and 12.2 each, respectively. It is worth noting that, although most people do seek support from health professionals, in areas where the accessibility to health centres is difficult as well as the availability of health infrastructure along closest corridors, people tend to rely on immediate alternative treatment (traditional healer and home treatment), as well as other alternative means. Equally, the main reasons behind the population influxes were investigated at the respective sites. The findings revealed that congregations of people are due to the following: market day (sporadic or nomadic) (16.4\%), religious festivals (15.8\%), worship services of either Temple, Church, or Mosque (12.8\%), markets set up in the locality (permanent or temporal basis), cultural festivals (11.4\% each), and crusade (9.4\%).

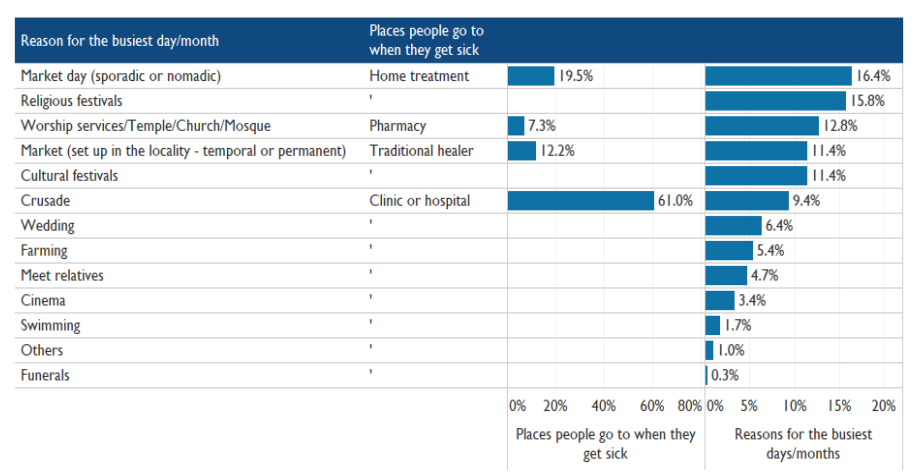

Figure 4.3: The major reasons for the busiest day/month (right) and the places people go to when they get sick (left)

During the Ebola outbreaks in West Africa (Sierra Leone), a data tracking matrix was conducted across the border (between Guinea and Sierra Leone). We deduced a week analysis to and fro Sierra Leone and Guinea for both male and female travelers (both under 5 and above). The data shows (see Figure 1) that females travel most frequently than their male counterparts. This can be attributed to the fact that the first Ebola case passes from Guinea to Sierra Leone through the Gblamuya border. Thus, human mobility contributes greatly to the spread of infectious diseases, and this is evident from previous outbreaks (Spanish flu, SARS-CoV-2, MERS, and COVID-19). 


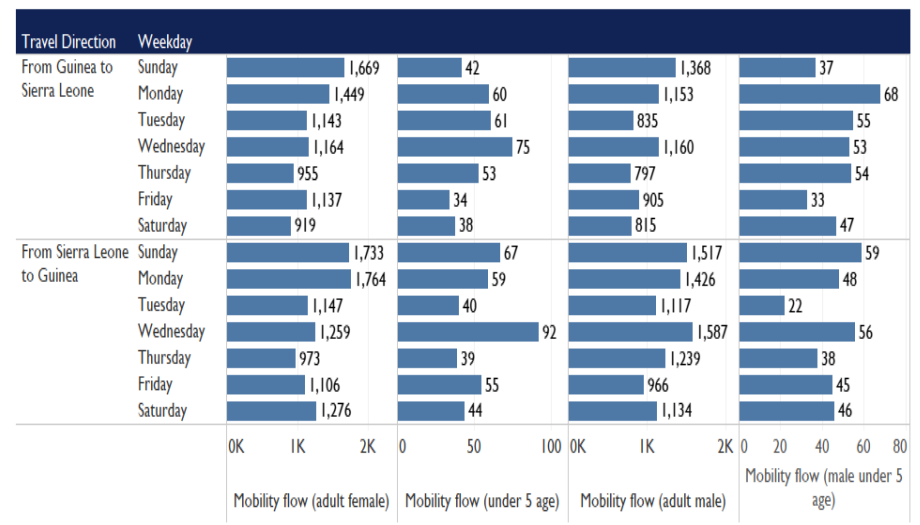

Figure 4.4: Population and mobility patterns during the Ebola outbreak in West Africa (Sierra Leone border with Guinea)

\section{CONCLUSIONS AND FUTURE WORK}

In reflection of informatics requires in an outbreak setting or pandemic initiate with strategic planning and a review of well described pandemic preparedness and response protocols from established agencies such as WHO and the Centres for Disease Control and Prevention (CDC, and other health organization. Consequently, to constantly evolving recommendations from such agencies that specifically pertain to COVID-19, there is publicly available information on pandemic responses comprehensively. Literature detailing responses taken into consideration and to mitigate previous influenza, Ebola, MERs etc., provide useful framework to respond to future challenges in the healthcare domain.

However, adequate technique is required to establish method that best address health challenges during an outbreak or pandemic in regard to human population mobility matrix. We present a theoretical and practical approaches through simulation exercises. Some of the simulation results were presented and evaluated through the adaptation HPMM algorithm. With the effect of multiple institutions across the world transitioned to telemedicine in an effort to mitigate emergency room visits through remote triaging. Telemedicine has already demonstrated its usefulness during epidemiological emergencies such aa live video counseling with patients, virtual patient monitoring, and mobile applications for symptom observations. The results obtained from the analysis indicates that human mobility contribute enormously to the spread of infectious diseases. Furthermore, the tendency of unusual practice (the case of traditional healers) contributes positively and negatively to the spread of infectious diseases and vulnerability space for localities where health infrastructure is lacking (pure water, health facilities etc.).

Future work for this proposed methodology will look at pattern recognition and data mining technique that will help predict emerging diseases based on the current or exiting diseases at a specific locality. The proposed HPMM algorithm is designed and implemented as a case study base on existing data in some border areas between Sierra Leone and Guinea and between Nepal and India. 


\section{REFERENCES}

[1] Alhazzani, W., Møller, M.H., Arabi, Y.M., Loeb, M., Gong, M.N. and Fan, E., \& Du, B. (2020). Surviving Sepsis Campaign: guidelines on the management of critically ill adults with Coronavirus Disease 2019 (COVID-19). Intensive care medicine, pp.1-34.

[2] Lu, R., XZ (January 30, 2020). Genomic characterization and epidemiology of the 2019 novel coronavirus: implications for virus origins and receptor binding. The Lancet, 395 (10224), pp. 566-568.

[3] Proclamation on declaring a national emergency Concerning the Novel Coronavirus Disease (COVID-19) Outbreak. https://www.whitehouse.gov/presidentialactions/proclamation-declaring-national-emergencyconcerningnovel-coronavirus-disease-covid-19outbreak/Accessed March 13, 2020.

[4] Guan, W.J., Ni, Z.Y., Hu, Y., Liang, W.H., Ou, C.Q., He, J.X., Liu, L., Shan, H., Lei, C.L., Hui, D.S. and Du, B., 2020. Clinical characteristics of coronavirus disease 2019 in China. New England journal of medicine, 382(18), pp.17081720 .

[5] Centers for Disease Control and Prevention, 2020. Centers for Disease Control and Prevention Coronavirus disease 2019 (COVID-19) 2020.

[6] Atreja, A., Gordon, S.M., Pollock, D.A., Olmsted, R.N. and Brennan, P.J., 2008. Opportunities and challenges in utilizing electronic health records for infection surveillance, prevention, and control. American journal of infection control, 36(3), pp.S37-S46.

[7] Joshi AU, Randolph FT, Chang AM, et al. Impact of emergency department tele-intake on left without being seen and throughput metrics. Acad Emerg Med 2020; 27 (2): 139-47.

[8] Langabeer JR, Gonzalez M, Alqusairi D, et al. Telehealth-enabled emergency medical services program reduces ambulance transport to urban emergency departments. West J Emerg Med 2016; doi: 10.5811/westjem.2016.8.30660.

[9] Hollander JE, Carr BG. Virtually perfect? Telemedicine for Covid-19. N Engl J Med 2020; 1-3. Lurie N, Carr BG. The role of telehealth in the medical response to disasters. JAMA Intern Med 2018; 178 (6): 745.

[10] Dong E, Du H, Gardner L. An interactive web-based dashboard to track COVID-19 in real time. Lancet Infect Dis 2020; 3099 (20): 19-20.

[11] Fidler DP, Gostin LO. The WHO pandemic influenza preparedness framework: a milestone in global governance for health. JAMA J Am Med Assoc 2011; 306 (2). doi: 10.1001/jama.2011.960

[12] Tognotti, E., 2009. Influenza pandemics: a historical retrospect. The Journal of Infection in Developing Countries, 3(05), pp.331-334.

[13] Crosby, A.W., 2003. America's forgotten pandemic: the influenza of 1918. Cambridge University Press.

[14] Taubenberger, J.K., Hultin, J.V. and Morens, D.M., 2007. Discovery and characterization of the 1918 pandemic influenza virus in historical context. Antiviral therapy, 12(4 Pt B), p.581.

[15] Spellberg, B., Guidos, R., Gilbert, D., Bradley, J., Boucher, H.W., Scheld, W.M., Bartlett, J.G., Edwards Jr, J. and Infectious Diseases Society of America, 2008. The epidemic of antibiotic-resistant infections: a call to action for the medical community from the Infectious Diseases
Society of America. Clinical infectious diseases, 46(2), pp.155-164.

[16] Bodenheimer, T., 2008. Coordinating care-a perilous journey through the health care system.

[17] Li, J., Brock, J., Jack, B., Mittman, B., Naylor, M., Sorra, J., Mays, G. and Williams, M.V., 2016. Project ACHIEVE-using implementation research to guide the evaluation of transitional care effectiveness. BMC health services research, 16(1), pp.1-9.

[18] Heavin, C., 2017. Health information systemsopportunities and challenges in a global health ecosystem. Journal of the Midwest Association for Information Systems| Vol, 2017(2), p.1.

[19] Bygstad, B., O. Hanseth, and D.T. Le. "From IT Silos to Integrated Solutions. A Study in E-Health Complexity." in ECIS. 2015.

[20] Kobusinge, G., et al. "The (Missing?) Role of Health Information Systems (HIS) in Patient Care Coordination and Continuity (PCCC): The Case of Uganda." in International Conference on e-Infrastructure and e-Services for Developing Countries. 2018. Springer.

[21] Butt, T.A., Iqbal, R., Salah, K., Aloqaily, M. and Jararweh, Y., 2019. Privacy management in social internet of vehicles: review, challenges and blockchain based solutions. IEEE Access, 7, pp.79694-79713.

[22] Adenuga, O.A., R.M. Kekwaletswe, and A. Coleman, "eHealth integration and interoperability issues: towards a solution through enterprise architecture." Health information science and systems, 2015. 3(1): p. 1-8.

[23] Naudet, Y. and D. Chen, "eHealth interoperability evaluation using a maturity model." Quality of Life Through Quality of Information: Proceedings of MIE2012, 2012. 180: p. 333.

[24] Valatavičius, A. and S. Gudas, "Towards the deep, knowledge-based interoperability of applications." Informacijos mokslai, 2017. 79(79): p. 83-113.

[25] Affleck, E., 2019. Interoperability of electronic medical records requires more than just technical understanding. CMAJ, 191(19), pp. E541-E541.

[26] Benson, T. and Grieve, G., 2016. Principles of Health Interoperability. Springer.

[27] Al-Kofahi, M.K., Hassan, H., Mohamad, R., Intan, T.P. and Com, M., 2020. Information systems success model: A review of literature. International Journal of Innovation, Creativity and Change, 12 .

[28] Leal, G.S., Guédria, W. and Panetto, H., 2020. Enterprise interoperability assessment: a requirement engineering approach. International Journal of Computer Integrated Manufacturing, 33(3), pp.265-286.

[29] Kalogirou, V. and Charalabidis, Y., 2019. The European union landscape on interoperability standardisation: status of European and national interoperability frameworks. In Enterprise Interoperability VIII (pp. 359-368). Springer, Cham.

[30] Li, J., Ullah, A., Li, J., Nazir, S., Khan, H.U., Ur Rehman, H. and Haq, A.U., 2020. Attributes-based decision making for selection of requirement elicitation techniques using the analytic network process. Mathematical Problems in Engineering, 2020.

[31] Novo, O. and Francesco, M.D., 2020. Semantic interoperability in the IoT: Extending the Web of things architecture. ACM Transactions on Internet of Things, 1(1), pp.1-25. 
ISSN 2250-3153

[32] Saputro, R., Pappel, I., Vainsalu, H., Lips, S. and Draheim, D., 2020, April. Prerequisites for the adoption of the X-Road interoperability and data exchange framework: a comparative study. In 2020 Seventh International Conference on eDemocracy \& eGovernment (ICEDEG) (pp. 216-222). IEEE.

[33] Cresswell, K., Williams, R. and Sheikh, A., 2020. Developing and applying a formative evaluation framework for health information technology implementations: qualitative investigation. Journal of medical Internet research, 22(6), p.e15068.

[34] Seebregts, C., Dane, P., Parsons, A.N., Fogwill, T., Rogers, D., Bekker, M., Shaw, V. and Barron, P., 2018. Designing for scale: optimising the health information system architecture for mobile maternal health messaging in South Africa (MomConnect). BmJ global health, 3(Suppl 2), p.e000563.

[35] West, C., 2016. Designing Solutions. International Educator, 25(4), p.22.

[36] Chen, D. and N. Daclin. Framework for enterprise interoperability. in Proc. of IFAC Workshop EI2N. 2006. sn. [37] Harvey, F., Designing for interoperability: Overcoming semantic differences, in Interoperating Geographic Information Systems. 1999, Springer. p. 85-97.

[38] Rauffet, P., C. Da Cunha, and A. Bernard. "Designing and managing Organizational Interoperability with organizational capabilities and roadmaps." in Interoperability for Enterprise Software and Applications China, 2009. IESA'09. International Conference on. 2009. IEEE.

[39] Salas, P.E., et al. "Interoperability by design using the StdTrip tool: an a priori approach." in Proceedings of the 6th International Conference on Semantic Systems. 2010. ACM. [40] Sheth, A.P., 1999. Changing focus on interoperability in information systems: from system, syntax, structure to semantics. In Interoperating geographic information systems (pp. 5-29). Springer, Boston, MA.

[41] HIMSS, Dictionary of Healthcare Information Technology Terms, Acronyms and Organizations, p. 75. 3rd ed. 2013.

[42] ISO, Interoperability of telehealth systems and networks- - Part 1: Introduction and definitions, in ISO/TR 16056-1:2004 Health informatics -- 2004.

[43] Solotruk, M. and M. Krištofič, "Increasing the degree of information system integration and developing an integrated information system." Information \& Management, 1980. 3(5): p. 207-212.

[44] Kobusinge, G., 2020. Putting interoperability on healthinformation-systems' implementation agenda.

[45] Shin, N. and Edington, B.H., 2007. An integrative framework for contextual factors affecting information technology implementation. Journal of Information Technology Theory and Application (JITTA), 8(4), p.4.

First Author: Abdul Joseph Fofanah is with the Department of Mathematics \& Computer Science, Faculty of Environmental Sciences, Milton Margai College of Education and Technology. In 2008, he received an Associate Degree in Mathematics at the Milton Margai College of Education and Technology now "Milton Margai Technical University", in 2013 he attained a B. Sc (Hons.) in Computer Science, in 2018 he received a master's degree in Computer Science at Njala University, and in 2020 he attained a Master's in Software Engineering at Nankai University, China, and currently he is pursuing his Ph.D. program in Information Health Systems at the Atlantic International University. From 2009-date he has worked as a lecturer and researcher at MMCET now MMTU,

This publication is licensed under Creative Commons Attribution CC BY.

http://dx.doi.org/10.29322/IJSRP.11.10.2021.p11818
Freetown, Sierra Leone. He has also worked for the International Organization for Migration as Data and GIS Officer and as a consultant. During the multiple outbreaks in West Africa, he attained the position of Data Scientist, where he was managing migration data across the region. As a result of his outstanding performance, he was sent to Kenya to manage mobility tracking mechanism during their flooding deserter including the COVID-19 pandemic in Nepal and Afghanistan

Second Author: Issa Fofana (Ph.D.), Lecturer, Department of Physics and Computer Science, Njala University. He obtained B.Sc. (Ed) Physics and Mathematics - Njala University College, University of Sierra Leone in 1980, taught Physics and Mathematics in secondary schools from 1980 to 1984. Attained M.Sc., and Ph.D. in Applied Physics, Technical University of Wroclaw, Poland in 1987 and 1992, respectively. Employed as a lecturer in the Department of Physics in 1992. Head of Department, Department of Physics 2004-2010, where he transformed the department and had it retitled Physics and Computer Science. Acted as Dean School of Technology, from 2010 - 2013.

Third Author: Saidu Koroma was formerly the Head of Department of Mathematics \& Computer Science in the Faculty of Environmental Sciences, Milton Margai College of Education and Technology (MMCET), Goderich Campus, Freetown, Sierra Leone. Currently, he is the Dean of Faculty of Environmental Sciences. He studied at Njala University College, University of Sierra Leone (NUC/USL) and attained a B.Sc. degree in Agriculture General. In 1996, he attained a Diploma in Data Processing at the Institute of Public Administration and Management, University of Sierra Leone (IPAM/USL). In 2003/2004 academic year, he pursued a Master of Science (M.Sc.) degree in Development Studies. In 2013, he attained Certificates in Computer Networking (C+, A+, CCNA and MCITP), Linux Administration and IT Security at UTL, Bangalore, India. In 2021, he also completed a Master of Science (M.Sc.) program in Information Systems Management at Njala University and is awaiting result. In 1998, he worked as a Teacher at the Harford Secondary School for Girls and in 1999, he was employed as Programme Manager at the Jesus Healing Ministries, a Local NGO, Committed to Community Development and Evangelism. $\mathrm{He}$ has also been involved in some research work for various organizations. He was however, employed at MMCET now Milton Margai Technical University (MMTU) as Lecturer in the year 2000 , where he rose through the ranks. 